\title{
The Effect of Zingiber officinale Roscoe (Ginger) on Dentin Microhardness: An in vitro Study
}

\author{
Siti Khadijah Mohd Zaki ${ }^{1,3}$, Safura Anita Baharin ${ }^{1}$, Jasmina Qamaruz Zaman ${ }^{1}$, Hsu Zenn Yew ${ }^{1}$ \\ \& Shahida Mohd Said ${ }^{2}$ \\ 1 Department of Operative Dentistry, Faculty of Dentistry, Universiti Kebangsaan Malaysia, Kuala Lumpur, \\ Malaysia \\ ${ }^{2}$ Department of Periodontology, Faculty of Dentistry, Universiti Kebangsaan Malaysia, Kuala Lumpur, Malaysia \\ ${ }^{3}$ Oral Health Division, Ministry of Health Malaysia, Kuala Lumpur, Malaysia \\ Correspondence: Safura Anita Baharin, Department of Operative Dentistry, Faculty of Dentistry, Universiti \\ Kebangsaan Malaysia, Kuala Lumpur, Malaysia. Tel: 60-392-897-759. E-mail: safurabaharin@ukm.edu.my
}

Received: October 3, 2017

doi:10.5539/jas.v9n13p102

\author{
Accepted: December 18, 2017 Online Published: December 31, 2017 \\ URL: https://doi.org/10.5539/jas.v9n13p102
}

This research is financed by the Young Researcher Incentive Grant, UKM (GGPM 2014-020).

\begin{abstract}
It has been established that conventional root canal irrigants cause detrimental effect on the physico-chemical properties of root dentin. This study aims to determine the effect of a novel root irrigant, ginger or Zingiber officinale Roscoe essential oil on root dentin microhardness. Eighty root halves of extracted human teeth were used and prepared by embedding them individually in autopolymerizing acrylic resin. These samples were then divided into four groups $(\mathrm{n}=20$ each), i.e., i) $0.5 \%$ Z. officinale Roscoe oil, ii) $2.5 \%$ sodium hypochlorite ( $\mathrm{NaOCl}$, positive control), iii) $17 \%$ ethylenediaminetetraacetic acid (EDTA, positive control) and iv) normal saline (negative control). Dentin microhardness was measured using Vickers Microhardness Tester with a $50 \mathrm{~g}$ load and a 10 -second dwell time, before and after immersion in respective solutions for 5 minutes. Measurements were taken in Vickers hardness number (VHN). All samples showed reduction in the microhardness reading; with Z. officinale Roscoe: 34.24 to 25.89 , NaOCl: 31.47 to 26.34 , EDTA: 33.08 to 26.04 and saline: 29.82 to $27.61 \mathrm{VHN}$. Although there was significant reduction within the $Z$. officinale Roscoe group $(p<0.001)$, the change was indifferent when compared among groups (post hoc Tukey's HSD test $p>0.05$ ). Within the limitations of this study, Zingiber officinale Roscoe essential oil does alter dentin microhardness but to a similar extent as $\mathrm{NaOCl}$ and EDTA.
\end{abstract}

Keywords: Zingiber officinale, dentin, irrigant, microhardness

\section{Introduction}

Root canal treatment requires eradication of pathogenic microorganisms and its by-products from the complicated root canal system (Siqueira et al., 2000). These microorganisms and their toxic derivatives are the primary causative factors in the development of pulpal necrosis and consequently the emergence of periapical lesions (Nair, 2004). The use of mechanical debridement alone in root canal treatment was found ineffective to thoroughly eliminate these microorganisms thus it is necessary to combine with chemical cleansing to ensure favorable treatment outcome (Paqué et al., 2009, 2010). Irrigating the root canal with antibacterial irrigant allows effective removal of necrotic tissues, dentinal debris and microorganisms together with its by-products especially in the root canal irregularities and dentinal tubules.

At present, irrigants that are commonly used in root canal treatment includes sodium hypochlorite $(\mathrm{NaOCl})$, ethylenediamine tetraacetic acid (EDTA) and chlorhexidine. It is well established that amongst the ideal characteristics of an irrigant are able to eradicate anaerobic and facultative microorganisms, inactivating their toxic by-products as well as incapable to induce any untoward effects on the biomechanical properties of root canal dentin (Basrani \& Haapasalo, 2012). Some of the important biomechanical properties of dentin includes its hardness and fracture toughness by which can be measured through Vickers and Knoop indentations tests (Meredith et al., 1996). Hardness allows us to evaluate the effects of physical and/or chemical agents have on dentin surfaces. 
It has been shown that sodium hypochlorite modifies the microstructural organization of the dentinal organic matrix which caused the reduction of the elasticity and flexural strength of endodontically treated teeth. In addition, sodium hypochlorite also has a deleterious effect on collagen and proteoglycans, which further enhances the reduction of the mechanical resistance of dentin (Grigoratos et al., 2001). Meanwhile, extended contact time with EDTA will damage the peritubular and intertubular dentin which resulted in erosion of the dentin surface (Marending et al., 2007; Mai et al., 2010).

\subsection{Natural Products as an Alternative Endodontic Irrigant}

Researchers has been exploring and enhancing the potential use of therapeutic chemicals extracted from herbal derivatives. Many plants have been addressed in literature as prospective sources for therapeutic alternatives in endodontics to inhibit or suppress microorganisms and eliminate their noxious by-products.

However, limited information is available on the effect of such herbal derivatives on the physical properties of root dentin. If changes in the dentin microhardness is less or at the very least comparable to sodium hypochlorite and EDTA, this natural product has the potential to substitute the conventional irrigants commonly used in root canal treatment. Therefore, this study is expected to envision the performance of this natural product compared to the existing synthetic irrigants.

\subsection{Zingiber officinale Roscoe (Ginger)}

Ginger is well known as a condiment used in food and beverage as well as an herbal remedy due to its distinctive taste and aroma. It belongs to the Zingiberaceae family and other notable members of this plant family are turmeric, cardamom and galangal. Ginger is also used in traditional complementary medicine to help treat the common cold, colic, diarrhea and indigestions (Ali et al., 2008).

The active components of the $Z$. officinale Roscoe root are volatile oils and pungent phenol compounds, such as gingerols and shogaols which comprises approximately $1-3 \%$ of its weight. The concentrations of its active ingredients may differ with growing conditions. Gingerols possess analgesic, sedative, anti-pyretic and anti-bacterial effects in-vitro and in animals (Mascolo, 1989; Ojewole et al., 2006). The constituents of [6]-gingerol and [12]-gingerol, which are isolated from the rhizome, have shown antibacterial activities against selected periodontal bacteria (Park et al., 2008; Rahmani et al., 2014).

The methanol extract of $Z$. officinale Roscoe rhizomes was reported to exhibit significant antibacterial actions against $E$. coli, Salmonella enteriditis and $S$. aureus during an in-vitro investigation (Kumari et al., 2009). In a study by Valera et al. (2016), it was suggested that $Z$. officinale Roscoe may be clinically applicable as a root canal irrigant as $20 \% Z$. officinale glycolic extracts were effective in reducing the endotoxins and microorganisms implicated in endodontic infections such as Candida albicans and Enterococcus faecalis.

To the best of the authors' knowledge, there is no study on the effect of this novel irrigant on dentin microhardness. Furthermore, it is imperative to explore the effect of this irrigant onto the physical and mechanical properties of dentin as significant changes in the dentinal properties may adversely affect the overall strength, decrease the modulus of elasticity and flexural strength values which consequently diminishes the fracture resistance of the root (Uzunoglu et al., 2012). As dentin supports enamel, a softer dentin tissue becomes less efficient, allowing the occurrence of fractures and cracks in the enamel (Gonçalves et al., 2014). Additionally, changes in the physico-chemical properties of dentin can also affect the adhesion and sealing ability of dental materials within the root canal system (Sayin et al., 2007).

\subsection{Aim and Objective}

The aim of this study is to determine the effect of $Z$. officinale Roscoe oil on dentin microhardness against commonly used endodontic irrigants which are sodium hypochlorite and EDTA. The null hypothesis of this study was that there was no significant difference between the effects of $Z$. officinale Roscoe on dentin microhardness compared to sodium hypochlorite and EDTA.

\section{Methodology}

Ethics approval was obtained from the Universiti Kebangsaan Malaysia (UKM) ethics committee [UKM 1.5.3.5/244/JEP-2016-083] to conduct this study at the Simulation Laboratory and Dental Material Laboratory, Faculty of Dentistry UKM as well as utilizing the facilities at the Faculty of Health Sciences UKM and Morphology Laboratory, Center for Research and Instrumentation (CRIM), UKM. All laboratory procedures were performed by a single operator under close supervision by experienced restorative dentistry specialists, endodontic specialist and a research laboratory technician. Sample size calculated was achieved using the sample size calculator application, G*Power statistical power analysis tool version 3.1 (http://www.gpower.hhu.do). This is 
based on the statistical test used and the value was determined to produce an $80 \%$ power of study with $\alpha=0.05$ with a two-sided significance level. Effect size was estimated at $80 \%$.

A total of forty extracted sound human mandibular premolar teeth were assigned for measurement of dentin microhardness test. The selected teeth must have completed root formation, non-carious, no signs of root resorption and not endodontically treated. Teeth with any structural abnormalities, cracks, caries, extensive restorations, sclerotic canals, open apices or with curved root beyond $10^{\circ}$ were excluded from selection. Teeth were then divided into four groups of equal numbers of sample (10 teeth in each group), cleaned from soft and hard attached tissues by using Gracey's curette, and immersed in 10\% neutral buffered formalin solution for seven days as a disinfection protocol (Dominici et al., 2001). The teeth were stored in the same solution throughout the study to minimize dentinal permeability changes for up to 6 months (Lee et al., 2007).

\subsection{Preparation of Experimented Irrigants}

Z. officinale Roscoe oil was prepared using the hydro distillation method (Ali et al., 2002; Jantan et al., 2003). The concentration selected for this study was based on the respective minimum inhibitory concentration (MIC) and minimum bactericidal concentration (MBC) established in previous studies (Azizi et al., 2015; Lopez et al., 2005; Thosar et al., 2013) and has been reported to be effective against E. faecalis (Valera et al., 2015).

Rhizomes of $Z$. officinale Roscoe were obtained from a farm in Banting, Selangor, Malaysia. Approximately $500 \mathrm{~g}$ of fresh ginger rhizomes were washed thoroughly under running tap water and sliced into cross-sections at about 1 $\mathrm{mm}$ in thickness. The sliced ginger was subjected to hydro distillation in a Clevenger-type apparatus. The extraction was performed for 8 hours whilst maintaining the boiling point of the $1000 \mathrm{~mL}$ of distilled water in a $5 \mathrm{~L}$ flask at a constant temperature using a heating mantle as a heat source (Thermo-Scientific, Massachusetts, USA). The oil obtained was serially diluted using $95 \%$ ethanol to make a stock solution of $5 \mathrm{mg} / \mathrm{mL}$ and stored at $4{ }^{\circ} \mathrm{C}$ and protected from direct light exposure for subsequent use.

Sodium hypochlorite was obtained as the commercially-branded "Clorox" available on local supermarket shelves and manufactured by Clorox ${ }^{\circledR}$ Malaysia which contains a concentration of $5.25 \%$ chlorine. The solution was diluted to a concentration of $2.5 \%$ using equal parts of distilled water. The ethylenediaminetetraacetic acid (EDTA) solution was obtained from the brand "Pulpdent ${ }^{\circledR}$ " manufactured by which contains $17 \%$ EDTA in $60 \mathrm{~mL}$ bottle. This solution was acquired from the brand "Ain Medicare" manufactured by Ain Medicare, Malaysia, containing $0.9 \%$ sodium chloride in $500 \mathrm{~mL}$ container. Sodium hypochlorite and EDTA are positive control irrigants while normal saline is the negative control irrigant.

\subsection{Preparation of Specimens for Dentin Microhardness Measurement}

Each tooth was decoronated at the cementoenamel junction level using a high speed handpiece, diamond bur and cooled with distilled water. The sample length was not standardized. Pulp tissue was then removed using a barbed broach (Dentsply Maillefer, Ballaigues, Switzerland). The working length was determined using a size $10 \mathrm{~K}-\mathrm{File}$ (Dentsply Maillefer, Ballaigues, Switzerland) and negotiated until visible at the apical foramen. The teeth were prepared using the ProTaper ${ }^{\circledR}$ Universal Hand Files (Dentsply Maillefer, Ballaigues, Switzerland) in a crown down technique. The canals were prepared using the S1 and S2 files, followed by the finishing files from size F1 until F3. Patency filing was performed using a 10 K-File (Dentsply Maillefer, Ballaigues, Switzerland). The root canals were irrigated with distilled water at each file change with 30 seconds of irrigation time in each flush. Sterile paper points sizes ranged between 25 to 40 (Dentsply Maillefer, Ballaigues, Switzerland) were used to dry the canal (Cruz-Filho et al., 2011; Gupta et al., 2015; Kandil et al., 2014).

Following chemomechanical preparation of the root canal system, a groove was then created along the long axis of the tooth using a diamond disc (Komet Dental, Lemgo, Germany) and later split with a chisel and mallet. Each root half was horizontally embedded in an autopolymerizing acrylic resin (Vertex Dental, Zeist, Netherlands) using plastic molds in preparation to mount on the Vickers Microhardness Tester (HMV-2 FA; Shimadzu Corp., Tokyo, Japan). Each root half was flattened and polished using Buehler AutoMet ${ }^{\mathrm{TM}} 250$ Grinder Polisher with Buehler Carbimet ${ }^{\circledR} 2$ silicon carbide grinding paper grit 320/P400 (Buehler, Lake Bluff, IL, USA).

Each root specimen was placed on a Vickers Microhardness Tester (HMV-2 FA; Shimadzu Corp., Tokyo, Japan) for baseline measurement of microhardness and were taken in Vickers Hardness Number (VHN). Initial microhardness measurements were performed on the middle third of each root section at $100 \mu \mathrm{m}$ from the pulp-dentin interface and parallel to the root length. Three indentations spaced at $100 \mu \mathrm{m}$ apart were made on each specimen using a $50 \mathrm{~g}$ load and a 10-second dwell time (Cruz-Filho et al., 2001; De-Deus et al., 2006), resulting in an indentation pattern. The values were averaged to produce one VHN for each specimen. 
Twenty root specimens were immersed in the selected irrigants for $5 \mathrm{~min}$ in closed glass plates at $37{ }^{\circ} \mathrm{C}$ in an incubator (Kandil et al., 2014; Ulusoy \& Görgül, 2013). Approximately $5 \mathrm{~mL}$ of selected experimented irrigants were used in each glass plate to ensure root surfaces were adequately submerged in the irrigants. This is to standardize each specimen to the respective irrigants in a selected period of time which closely resembles the clinical exposure duration, similar to previous studies by Akcay and Sen (2012) and Ulusoy and Görgül (2013). Subsequently, the specimens were then removed from the glass plates and the root surfaces were immediately flushed with $10 \mathrm{~mL}$ of $0.9 \%$ normal saline (Ain Medicare, Malaysia) to remove any residual irrigant on the root surfaces. The root surfaces were dried with sterile gauze. Consequently, the specimens were again positioned on the Vickers Microhardness Tester (HMV-2 FA; Shimadzu Corp., Tokyo, Japan) for the post-treatment indentations in similar fashion to the baseline measurement within the vicinity of the initial indentation.

\subsection{Calculation of Dentin Microhardness Changes}

From the three indentations made on the pulp-dentin interface, the mean average of the measurements was obtained for both pre- and post-treatment readings. The change in dentin microhardness was analyzed as the difference between the baseline value compared to the post-treatment value in the experimented irrigants.

The Vickers Microhardness Tester (HMV-2 FA; Shimadzu Corp., Tokyo, Japan) through its featured software "HMV-FA" allows for an automated measurement of length through arbitrary positioning of the image and enables the indentation reading and calculation to be carried out immediately. The determined Vickers microhardness value, expressed as the Vickers Hardness Number (VHN) is according to the formula below:

$$
\mathrm{VHN}=1854.4 P / d^{2}
$$

where, $P=$ load, in grams and $d=$ mean diagonal of indentation in $\mu \mathrm{m}$.

\subsection{Intra-Examiner Reliability}

In order to establish the intra-examiner reliability, ten percent of the sample size were randomly selected for this purpose ( $\mathrm{n}=8$ samples). Paired $t$-test was utilized to evaluate the differences between the first measurement and the repeated measurement. The dentin microhardness measurements were reassessed after fourteen days by the same examiner. The result displayed that there was no significant difference in both of the dentin microhardness when measurements were repeated $(p>0.05)$.

\subsection{Statistical Analysis}

The results were explored and analyzed using IBM SPSS Data Editor Version 24.0. The data were primarily explored using Shapiro-Wilk test to assess the normality of the distribution. The data were normally distributed; hence the parametric tests which are paired $t$-test, mixed between-within subjects' analysis of variance (ANOVA) with repeated measures and post hoc Tukey's HSD test to detect any significant differences between the groups was performed. The mixed ANOVA statistical test was used to compare the dentin microhardness changes by the four groups of experimented irrigants across two phases, which are before and after immersion in the irrigants. In addition, significant differences between the group of experimented irrigants were checked using the Tukey's HSD post hoc test. The level of significance was set at $p<0.05$.

\section{Results}

A total of 80 root halves were measured for changes in the dentin microhardness.

\subsection{Measurement of Dentin Microhardness}

Table 1 shows mean differences in dentin microhardness measured in Vickers Hardness Number (VHN) and standard deviations (SD) before and after immersion with each experimented irrigants. Statistical analysis using paired $t$-test indicated that the reduction in microhardness was statistically significant $(p<0.05)$ for all experimented irrigants. 
Table 1. Dentin microhardness changes and standard deviations in VHN

\begin{tabular}{llllll}
\hline \multirow{2}{*}{ Irrigant } & \multicolumn{5}{c}{ Dentin microhardness in VHN } \\
\cline { 2 - 6 } & Baseline & Final & Mean difference & SD & $p$-value \\
\hline $2.5 \% \mathrm{NaOCl}$ & 31.47 & 26.34 & 5.13 & 4.34 & $<0.001$ \\
$17 \%$ EDTA & 33.75 & 26.04 & 7.72 & 6.92 & $<0.001$ \\
$0.9 \%$ Normal saline & 29.82 & 26.04 & 2.21 & 6.78 & 0.014 \\
$0.5 \%$ Z. officinale Roscoe & 34.24 & 25.89 & 8.35 & 8.50 & $<0.001$ \\
\hline
\end{tabular}

Note. $p$ is significant at $\alpha=0.05$.

All sample groups showed reduction in VHN, which indicated softening of dentin after immersion in tested irrigants. Although Z. officinale Roscoe oil showed the highest reduction in dentin microhardness (34.24 to 25.89 VHN), no statistically significant difference was observed between the experimented groups.

3.2 Comparison of Dentin Microhardness Changes between Z. officinale Roscoe Oil against Sodium Hypochlorite and EDTA

The mixed ANOVA result in Table 2 shows a statistically significant difference in dentin microhardness reduction before and after immersion, $F(1,354)=268.31, p<0.001$. However, there was no statistically significant difference in dentin microhardness with different types of irrigants tested $\mathrm{F}(5,354)=0.55, p=0.736$. It appears that the changes in dentin microhardness due to the effect of immersion is unrelated to the experimented irrigant tested $F(5,354)=6.12, p<0.001$.

Table 2. Interaction effects within and between type of irrigant groups and before and after immersion

\begin{tabular}{lllllll}
\hline Effect & df & Error df & Wilk's lambda & F-value & Effect size & $p$-value \\
\hline Immersion & 1 & 354 & 0.001 & 268.31 & 0.273 & $<0.001$ \\
Type of irrigant & 5 & 354 & & 0.55 & 0.008 & 0.736 \\
Immersion * Irrigant & 5 & 354 & 0.001 & 6.12 & 0.222 & $<0.001$ \\
\hline
\end{tabular}

Note. $p$ is significant at $\alpha=0.05$.

A post hoc Tukey's HSD test (Table 3) confirmed there was no statistically significant difference in dentin microhardness reduction $(p>0.05)$ when $Z$. officinale Roscoe oil was compared to all control groups.

Table 3. Comparison of $Z$. officinale Roscoe oil to control groups in dentin microhardness reduction

\begin{tabular}{llll}
\hline Irrigant & Irrigant & Mean difference & p-value \\
\hline Z. officinale Roscoe & Normal saline & 1.35 & 0.864 \\
& NaClO & 1.16 & 0.923 \\
& EDTA & 0.17 & 1.000 \\
\hline
\end{tabular}

Note. $p$ is significant at $\alpha=0.05$.

\section{Discussion}

In this study, the effect of $Z$. officinale Roscoe oil on dentin microhardness was measured and compared with two commonly used irrigants; $\mathrm{NaOCl}$ and EDTA. The results showed that this novel irrigant performed similarly with the conventional irrigants. Saline has also shown a significant change in dentin microhardness. However, the mean reduction with saline was not substantial and displayed the least changes compared to the other irrigants. This may be due to the absence of chelating or demineralizing effect of saline on the root dentin (Ballal et al., 2010; Grigoratos et al., 2001; Sim et al., 2001). On the other hand, the positive control irrigants, i.e., $\mathrm{NaOCl}$ and EDTA, showed significant reduction in dentin microhardness. This is in agreement with other studies which shows similar results (Ari et al., 2004; Cruz-Filho et al., 2011; Sayin et al., 2007; Slutzky-Goldberg et al., 2002). Sodium hypochlorite affects mechanical properties of dentin by damaging the organic dentin components and modifying the calcium/phosphate ratio within the radicular dentin (Basrani \& Haapasalo, 2012; Sim et al., 2001) while EDTA enables the decalcification of the inorganic portion of dentin (De-Deus et al., 2006). 
To date, there is no study specifically reporting the effects of $Z$. officinale Roscoe oil on dentin microhardness, making findings in this study preliminary in nature. In addition, there was no report available on the use of $Z$. officinale Roscoe oil alone as root canal irrigant. Previous studies used a combination of $Z$. officinale Roscoe extract together with other irrigants such as sodium hypochlorite, chlorhexidine and EDTA (Maekawa et al., 2013; Valera et al., 2015). Z. officinale Roscoe has also been supplemented with root canal medicament such as calcium hydroxide to substantiate the antibacterial effect of both materials (Maekawa et al., 2013; Valera et al., 2015). Furthermore, the explanation behind the effects of the chemical compounds in $Z$. officinale Roscoe towards dentin microhardness is yet to be completely understood. $Z$. officinale Roscoe is documented to have a detergent-like structure from its constituent, [10]-gingerol (Nagoshi et al., 2006), which may give rise to its low surface tension. A low surface tension could increase the wetting effect of the canal wall to permit deeper infiltration of the solution into the canal irregularities as well as enable an improved antimicrobial activity in uninstrumented areas of the canal system (Giardino et al., 2006). To reflect the actual duration of clinical exposure of root dentin to irrigant, a 5 -minute immersion time for each sample was chosen. The use of $0.5 \%$ of $Z$. officinale Roscoe oil in this study with the selected immersion time showed an acceptable microhardness change within the root canal as it is almost similar to the changes caused by sodium hypochlorite. In addition, the anti-inflammatory, antibacterial and antioxidant properties of this herbal extract can further enhance its positive and beneficial effect on the management of chronic periapical disease.

The demineralizing capacity in an irrigant is necessary to facilitate instrumentation to the apical portion of the root canal, especially in narrow and curved canals. Alteration of the organic and inorganic components of dentin surfaces through chemomechanical preparation through the loss of calcium ions, resulting in softening of the dentin layer adjacent to the root canal lumen. This allows the access of irrigating solution into the dentinal tubules for thorough disinfection (Doğan \& Çalt, 2001). On the positive side, this also provides access for irrigants to the area of root canal irregularities for better medicament delivery and effective obturation.

As the tubular density increases as it nears the pulp, there is also an increase in the area dominated by open tubules which are larger in diameter and without peritubular dentin (Pashley et al., 1985). As a result, the open tubules have little resistance to indentation compared to calcified intertubular dentin. Additionally, the intertubular dentin matrix near the pulp contain less mineral thus reducing the hardness of the dentin in this area (Kinney et al., 1996). Therefore, in order to minimize any structural differences between individual sample, the middle third of the root was selected as the location for the indentation test. Three indentations were made from the middle third of the root canal at a depth of $100 \mu \mathrm{m}$ from the pulp-dentin junction and spaced at $100 \mu \mathrm{m}$ from each indentation. Akcay and Sen (2012), and Oliveira et al. (2007) designated an equivalent configuration for the load and dwell time which was based on the inverse correlation between dentin microhardness and tubular density which was initially described by Pashley et al. (1985). Hence, a $50 \mathrm{~g}$ load with a 10 second dwell time through the Vickers Microhardness Tester was used (Akcay \& Sen, 2012; Oliveira et al., 2007).

The potential use of the rhizomes of $Z$. officinale Roscoe in root canal treatment shows promising results. Together with its anti-inflammatory, antimicrobial, antioxidant and analgesic properties, this natural product has the potential to be utilized and formulated to become a very effective irrigant for root canal treatment. Other favorable aspects of this plant as an alternative root canal irrigating solution are its negligible toxicity values and has a benign adverse reaction profile with an oral median lethal dose of $5 \mathrm{~g} / \mathrm{kg}$ (Chen et al., 2007). The plant is safe when ingested as proven by other studies which uses $Z$. officinale Roscoe extract to treat several systemic diseases such as arthritis and gastrointestinal discomfort (Ali et al., 2008). Additionally, a combination of several herbal extracts including $Z$. officinale Roscoe as a mouthwash has proven to be as effective as chlorhexidine mouthwash to treat gingivitis (Mahyari et al., 2016). This has also proven that these herbal extracts have an anti-inflammatory effect on inflamed tissue whilst not causing damage to the healthy tissues.

\section{Conclusion and Recommendations}

\subsection{Conclusion}

Within the limitation of this study, we can conclude that there was no significant difference between $0.5 \% Z$. officinale Roscoe oil compared to $2.5 \% \mathrm{NaOCl}$ and EDTA on dentin microhardness after a 5 -minute immersion period. The finding suggests that ginger oil is a promising and natural alternative to existing chemical irrigants in endodontics.

\subsection{Recommendations for Future Study}

Further increase in contact time of oil on the root surface during instrumentation may enable observation on potential erosive effects on the intertubular and peritubular dentin and changes on dentin microhardness. 


\section{Acknowledgements}

This research is financed by the Young Researcher Incentive Grant, UKM (GGPM 2014-020). All authors contributed equally to the study and preparation of this manuscript.

\section{References}

Akcay, I., \& Sen, B. H. (2012). The effect of surfactant addition to EDTA on microhardness of root dentin. Journal of Endodontics, 38(5), 704-707. https://doi.org/10.1016/j.joen.2012.02.004

Ali, B. H., Blunden, G., Tanira, M. O., \& Nemmar, A. (2008). Some phytochemical, pharmacological and toxicological properties of ginger (Zingiber officinale Roscoe): A review of recent research. Food and Chemical Toxicology, 46(2), 409-420. https://doi.org/10.1016/j.fct.2007.09.085

Ali, N. A. M., Mohtar, M., Shaari, K., Rahmanii, M., Ali, A. M., \& Jantan, I. B. (2002). Chemical composition and antimicrobial activities of the essential oils of Cinnamomum aureofulvum Gamb. Journal of Essential Oil Research, 14(2), 135-138. https://doi.org/10.1080/10412905.2002.9699798

Ari, H., Erdemir, A., \& Belli, S. (2004). Evaluation of the effect of endodontic irrigation solutions on the microhardness and the roughness of root canal dentin. Journal of Endodontics, 30(11), $792-795$. https://doi.org/10.1097/01.DON.0000128747.89857.59

Azizi, A., Aghayan, S., Zaker, S., Shakeri, M., Entezari, N., \& Lawaf, S. (2015). In-vitro effect of Zingiber officinale extract on growth of Streptococcus mutans and Streptococcus sanguinis. International Journal of Dentistry, 2015(1), 489842. https://doi.org/10.1155/2015/489842

Ballal, N. V., Mala, K., \& Bhat, K. S. (2010). Evaluation of the effect of maleic acid and ethylenediaminetetraacetic acid on the microhardness and surface roughness of human root canal dentin. Journal of Endodontics, 36(8), 1385-1388. https://doi.org/10.1016/j.joen.2010.04.002

Basrani, B., \& Haapasalo, M. (2012). Update on endodontic irrigating solutions. Endodontic Topics, 27(1), 74-102. https://doi.org/10.1111/etp.12031

Chen, J. C., Huang, L. J., Wu, S. L., Kuo, S. C., Ho, T. Y., \& Hsiang, C. Y. (2007). Ginger and its bioactive component inhibit enterotoxigenic Escherichia coli heat-labile enterotoxin-induced diarrhea in mice. Journal of Agricultural and Food Chemistry, 55(21), 8390-8397. https://doi.org/10.1021/jf071460f

Cruz-Filho, A. M., Sousa-Neto, M. D., Saquy, P. C., \& Pécora, J. D. (2001). Evaluation of the effect of EDTAC, CDTA, and EGTA on radicular dentin microhardness. Journal of Endodontics, 27(3), 183-184. https://doi.org/10.1097/00004770-200103000-00011

Cruz-Filho, A. M., Sousa-Neto, M. D., Savioli, R. N., Silva, R. G., Vansan, L. P., \& Pécora, J. D. (2011). Effect of chelating solutions on the microhardness of root canal lumen dentin. Journal of Endodontics, 37(3), 358-362. https://doi.org/10.1016/j.joen.2010.12.001

De-Deus, G., Paciornik, S., \& Mauricio, M. H. P. (2006). Evaluation of the effect of EDTA, EDTAC and citric acid on the microhardness of root dentine. International Endodontic Journal, 39(5), 401-407. https://doi.org/ 10.1111/j.1365-2591.2006.01094.x

Doğan, H., \& Çalt, S. (2001). Effects of chelating agents and sodium hypochlorite on mineral content of root dentin. Journal of Endodontics, 27(9), 578-580. https://doi.org/10.1097/00004770-200109000-00006

Dominici, J. T., Eleazer, P. D., Clark, S. J., Staat, R. H., \& Scheetz, J. P. (2001). Disinfection/sterilization of extracted teeth for dental student use. Journal of Dental Education, 65(11), 1278-1280.

Gernhardt, C. R., Eppendorf, K., Kozlowski, A., \& Brandt, M. (2004). Toxicity of concentrated sodium hypochlorite used as an endodontic irrigant. International Endodontic Journal, 37(4), 272-280. https://doi.org/10.1111/j.0143-2885.2004.00804.x

Giardino, L., Ambu, E., Becce, C., Rimondini, L., \& Morra, M. (2006). Surface tension comparison of four common root canal irrigants and two new irrigants containing antibiotic. Journal of Endodontics, 32(11), 1091-1093. https://doi.org/10.1016/j.joen.2006.05.008

Gonçalves, L. M. N., Palma-Dibb, R. G., Paula-Silva, F. W. G., de Oliveira, H. F., Nelson-Filho, P., da Silva, L. A. B., \& de Queiroz, A. M. (2014). Radiation therapy alters microhardness and microstructure of enamel and dentin of permanent human teeth. Journal of Dentistry, 42(8), 986-992. https://doi.org/10.1016/j.jdent. 2014.05.011 
Grigoratos, D., Knowles, J., Ng, Y. L., \& Gulabivala, K. (2001). Effect of exposing dentine to sodium hypochlorite and calcium hydroxide on its flexural strength and elastic modulus. International Endodontic Journal, 34(2), 113-119. https://doi.org/10.1046/j.1365-2591.2001.00356.x

Gupta, A., Duhan, J., Sangwan, P., Hans, S., \& Goyal, V. (2015). The effectiveness of three different plant extracts used as irrigant in removal of smear layer: a scanning electron microscope study. Journal of Oral Health and Community Dentistry, 1(3), 16-22.

Hauman, C. H. J., \& Love, R. M. (2003). Biocompatibility of dental materials used in contemporary endodontic therapy: A review. Part 2. Root-canal-filling materials. International Endodontic Journal, 36(3), 147-160. https://doi.org/10.1046/j.1365-2591.2003.00637.x

Hülsmann, M., Heckendorff, M., \& Schäfers, F. (2002). Comparative in-vitro evaluation of three chelator pastes. International Endodontic Journa, 35(8), 668-679. https://doi.org/10.1046/j.1365-2591.2002.00543.x

Jantan, I. B., Yassin, M. S. M., Chin, C. B., Chen, L. L., \& Sim, N. L. (2003). Antifungal activity of the essential oils of nine Zingiberaceae species. Pharmaceutical Biology, 41(5), 392-397. https://doi.org/10.1076/ phbi.41.5.392.15941

Kandil, H. E., Labib, A. H., \& Alhadainy, H. A. (2014). Effect of different irrigant solutions on microhardness and smear layer removal of root canal dentin. Tanta Dental Journal, 11(1), 1-11. https://doi.org/10.1016/ j.tdj.2014.03.001

Kinney, J. H., Balooch, M., Haupt Jr., D. L., Marshall, S. J., \& Marshall Jr., G. W. (1995). Mineral distribution and dimensional changes in human dentin during demineralization. Journal of Dental Research, 74(5), 1179-1184. https://doi.org/10.1177/00220345950740050601

Kumari, A. A., \& Promwichit, P. (2009). In-vitro antimicrobial evaluation of Zingiber officinale, Curcuma longa and Alpinia galanga extracts as natural food preservatives. Am J Food Technol, 4(5), 192-200. https://doi.org/ 10.3923/ajft.2009.192.200

Lee, J. J., Nettey-Marbell, A., Cook, A., Pimenta, L. A., Leonard, R., \& Ritter, A. V. (2007). Using extracted teeth for research: the effect of storage medium and sterilization on dentin bond strengths. The Journal of the American Dental Association, 12, 1599-1603. https://doi.org/10.14219/jada.archive.2007.0110

Lopez, P., Sanchez, C., Batlle, R., \& Nerin, C. (2005). Solid-and vapor-phase antimicrobial activities of six essential oils: Susceptibility of selected foodborne bacterial and fungal strains. Journal of Agricultural and Food Chemistry, 53(17), 6939-6946. https://doi.org/10.1021/jf050709v

Maekawa, L. E., Valera, M. C., Oliveira, L. D. D., Carvalho, C. A. T., Camargo, C. H. R., \& Jorge, A. O. C. (2013). Effect of Zingiber officinale and propolis on microorganisms and endotoxins in root canals. Journal of Applied Oral Science, 21(1), 25-31. https://doi.org/10.1590/1678-7757201302129

Mahyari, S., Mahyari, B., Emami, S. A., Malaekeh-Nikouei, B., Jahanbakhsh, S. P., Sahebkar, A., \& Mohammadpour, A. H. (2016). Evaluation of the efficacy of a polyherbal mouthwash containing Zingiber officinale, Rosmarinus officinalis and Calendula officinalis extracts in patients with gingivitis: A randomized double-blind placebo-controlled trial. Complementary Therapies in Clinical Practice, 22, 93-98. https://doi.org/10.1016/j.ctcp.2015.12.001

Mai, S., Kim, Y. K., Arola, D. D., Gu, L. S., Kim, J. R., Pashley, D. H., \& Tay, F. R. (2010). Differential aggressiveness of ethylenediamine tetraacetic acid in causing canal wall erosion in the presence of sodium hypochlorite. Journal of Dentistry, 38(3), 201-206. https://doi.org/10.1016/j.jdent.2009.10.004

Marending, M., Luder, H. U., Brunner, T. J., Knecht, S., Stark, W. J., \& Zehnder, M. (2007). Effect of sodium hypochlorite on human root dentine-mechanical, chemical and structural evaluation. International Endodontic Journal, 40(10), 786-793. https://doi.org/10.1111/j.1365-2591.2007.01287.x

Mascolo, N., Jain, R., Jain, S. C., \& Capasso, F. (1989). Ethnopharmacologic investigation of ginger (Zingiber officinale). Journal of Ethnopharmacology, 27(1-2), 129-140. https://doi.org/10.1016/0378-8741(89) 90085-8

Meredith, N., Sherriff, M., Setchell, D. J., \& Swanson, S. A. V. (1996). Measurement of the microhardness and Young's modulus of human enamel and dentine using an indentation technique. Archives of Oral Biology, 41(6), 539-545. https://doi.org/10.1016/0003-9969(96)00020-9 
Nagoshi, C., Shiota, S., Kuroda, T., Hatano, T., Yoshida, T., Kariyama, R., \& Tsuchiya, T. (2006). Synergistic effect of [10]-gingerol and aminoglycosides against vancomycin-resistant enterococci (VRE). Biological and Pharmaceutical Bulletin, 29(3), 443-447. https://doi.org/10.1248/bpb.29.443

Nair, P. N. R. (2004). Pathogenesis of apical periodontitis and the causes of endodontic failures. Critical Reviews in Oral Biology \& Medicine, 15(6), 348-381. https://doi.org/10.1177/154411130401500604

Ojewole, J. A. (2006). Analgesic, anti-inflammatory and hypoglycaemic effects of ethanol extract of Zingiber officinale (Roscoe) rhizomes (Zingiberaceae) in mice and rats. Phytotherapy Research, 20(9), 764-772. https://doi.org/10.1002/ptr.1952

Oliveira, L. D., Carvalho, C. A. T., Nunes, W., Valera, M. C., Camargo, C. H. R., \& Jorge, A. O. C. (2007). Effects of chlorhexidine and sodium hypochlorite on the microhardness of root canal dentin. Oral Surgery, Oral Medicine, Oral Pathology, Oral Radiology, and Endodontology, 104(4), e125-e128. https://oi.org/10.1016/ j.tripleo.2007.04.019

Paqué, F., Ganahl, D., \& Peters, O. A. (2009). Effects of root canal preparation on apical geometry assessed by micro-computed tomography. Journal of Endodontics, 35(7), 1056-1059. https://doi.org/10.1016/j.joen.2009. 04.020

Paqué, F., Zehnder, M., \& Marending, M. (2010). Apical fit of initial K-files in maxillary molars assessed by micro-computed tomography. International Endodontic Journal, 43(4), 328-335. https://doi.org/10.1111/ j.1365-2591.2010.01685.x

Park, M., Bae, J., \& Lee, D. S. (2008). Antibacterial activity of [10]-gingerol and [12]-gingerol isolated from ginger rhizome against periodontal bacteria. Phytotherapy Research, 22(11), 1446-1449. https://doi.org/ 10.1002/ptr.2473

Pashley, D., Okabe, A., \& Parham, P. (1985). The relationship between dentin microhardness and tubule density. Dental Traumatology, 1(5), 176-179. https://doi.org/10.1111/j.1600-9657.1985.tb00653.x

Rahmani, A. H. (2014). Active ingredients of ginger as potential candidates in the prevention and treatment of diseases via modulation of biological activities. International Journal of Physiology, Pathophysiology and Pharmacology, 6(2), 125. https://doi.org/10.5530/pj.2017.5.109

Saleh, A. A., \& Ettman, W. M. (1999). Effect of endodontic irrigation solutions on microhardness of root canal dentine. Journal of Dentistry, 27(1), 43-46. https://doi.org/10.1016/s0300-5712(98)00018-9

Sayin, T. C., Serper, A., Cehreli, Z. C., \& Otlu, H. G. (2007). The effect of EDTA, EGTA, EDTAC, and tetracycline- $\mathrm{HCl}$ with and without subsequent $\mathrm{NaClO}$ treatment on the microhardness of root canal dentin. Oral Surgery, Oral Medicine, Oral Pathology, Oral Radiology, and Endodontology, 104(3), 418-424. https://doi.org/10.1016/j.tripleo.2007.03.021

Sim, T. P. C., Knowles, J. C., Ng, Y. L., Shelton, J., \& Gulabivala, K. (2001). Effect of sodium hypochlorite on mechanical properties of dentine and tooth surface strain. International Endodontic Journal, 34(2), $120-132$. https://doi.org/10.1046/j.1365-2591.2001.00357.x

Siqueira, J. F., Rôças, I. N., Favieri, A., \& Lima, K. C. (2000). Chemomechanical reduction of the bacterial population in the root canal after instrumentation and irrigation with $1 \%, 2.5 \%$, and $5.25 \%$ sodium hypochlorite. Journal of Endodontics, 26(6), 331-334. https://doi.org/10.1097/00004770-200006000-00006

Slutzky-Goldberg, I., Liberman, R., \& Heling, I. (2002). The effect of instrumentation with two different file types, each with $2.5 \% \mathrm{NaClO}$ irrigation on the microhardness of root dentin. Journal of Endodontics, 28(4), 311-312. https://doi.org/10.1097/00004770-200204000-00012

Stoward, P. J. (1975). A histochemical study of the apparent deamination of proteins by sodium hypochlorite. Histochemistry and Cell Biology, 45(3), 213-226. https://doi.org/10.1007/bf00507696

Thosar, N., Basak, S., Bahadure, R. N., \& Rajurkar, M. (2013). Antimicrobial efficacy of five essential oils against oral pathogens: An in vitro study. European Journal of Dentistry, 7(Suppl. 1), S71. https://doi.org/10.4103/ $1305-7456.119078$

Uzunoglu, E., Aktemur, S., Uyanik, M. O., Durmaz, V., \& Nagas, E. (2012). Effect of ethylenediaminetetraacetic acid on root fracture with respect to concentration at different time exposures. Journal of Endodontics, 38(8), 1110-1113. https://doi.org/10.1016/j.joen.2012.04.026

Valera, M. C., Oliveira, S. A., Maekawa, L. E., Cardoso, F. G., Chung, A., Silva, S. F., \& Carvalho, C. A. (2016). Action of chlorhexidine, Zingiber officinale, and calcium hydroxide on Candida albicans, Enterococcus 
faecalis, Escherichia coli, and endotoxin in the root canals. $J$ Contemp Dent Pract, 17(2), 114-8. https://doi.org/10.5005/jp-journals-10024-1812

Yang, Z. N., Yang, W., Peng, Q., He, Q., Feng, Y., Luo, S., \& Yu, Z. (2009). Volatile phytochemical composition of rhizome of ginger after extraction by headspace solid-phase microextraction, petrol ether extraction and steam distillation extraction. Bangladesh Journal of Pharmacology, 4(2), 136-143. https://doi.org/10.3329/ bjp.v4i2.3232

\section{Copyrights}

Copyright for this article is retained by the author(s), with first publication rights granted to the journal.

This is an open-access article distributed under the terms and conditions of the Creative Commons Attribution license (http://creativecommons.org/licenses/by/4.0/). 